\title{
ERUV: A HETEROTOPIA JUDAICA
}

\author{
Isabel Arco Verde Santos* \\ (Universidade do Estado do Rio de Janeiro)
}

\begin{abstract}
RESUMO: O Eruv é uma forma de ampliação do espaço de circulação com transporte de objetos durante as leis de Shabat, que determinam a necessidade do descanso e de não haver trabalho neste tempo . Foucault nos ajuda a entender a sua dimensão dessa ideia, com o desenvolvimento do conceito de heterotopia.
\end{abstract}

Palavras-CHAVE: Eruv; shabat; heterotopia

\section{ERUV: THE JEWISH HETEROTOPIA}

\begin{abstract}
Eruv is a way of expanding the circulation space with the transport of objects during the Shabbat laws, which determine the need for rest and no work at this time. Foucault helps us to understand its dimension of this idea, with the development of the concept of heterotopy.
\end{abstract}

KEYWORDS: Eruv; shabat; heterotopia

Em hebraico, a raiz 'arab (ayin, resh, beit) tem uma multiplicidade de aplicações. Muitas de suas acepções estão ligadas à ideia de mistura ou mescla. É assim, quando usamos a forma tão corriqueira que designa o período do dia que traduzimos por tarde. Podemos entender que a tarde é uma mescla do dia e da noite, um período intermediário entre a luz e a escuridão.

Há uma designação para esta raiz, objeto deste trabalho, que tem uma utilização muito peculiar na religiosidade judaica. Trata-se do eruv, que é uma forma de ampliar as possibilidades de ação na interpretação de determinadas leis judaicas.

Há três tipos de eruv: o eruv chatzerot (mistura dos pátios), o eruv tavshlin (eruv dos cozimentos) e o eruv tchumin (mistura dos limites). Todos estes eruvin (plural de eruv, em aramaico) estão associados às leis que regem as ações de guarda dos dias sagrados. Geralmente ligados ao Shabat, mas não só, pois também têm aplicação em qualquer dia considerado sagrado e para o qual espera-se a observância das leis de descanso (não trabalho). Isso acontece por razões milenares, primitivamente associadas ao mandamento sagrado de guarda do sábado, contido no decálogo, como se lê:

Lembra-te do dia de sábado para santificá-lo. Trabalharás durante seis dias, e farás toda a tua obra. O sétimo dia, porém, é o sábado de Iahweh teu Deus. Não farás nenhum trabalho, nem tu, nem teu filho, nem tua filha, nem teu escravo, nem tua escrava, nem teu animal, nem teu estrangeiro que está em tuas portas. Porque em

\footnotetext{
*E-mail: verdesantos@uol.com.br.
} 
seis dias Iahweh fez o céu, a terra, o mar e tudo o que eles contêm, mas repousou no sétimo dia: por isso Iaweh abençoou o dia de sábado e o santificou. ${ }^{1}$

O problema ocorre na interpretação daquilo que significaria guardar o sábado, já que o texto bíblico explica que obedecer a este mandamento significa, acima de tudo, não trabalhar. Daí começam a surgir diversos questionamentos, alguns inclusive que vão ser tema de abordagens nos evangelhos, apresentando as posturas de Jesus para o assunto. ${ }^{2}$

$\mathrm{Na}$ antiguidade bíblica, infringir as leis de descanso que celebravam a o Shabat seriam punidos com a morte. Decerto, em Números 15 é narrada a história de um homem, que no período em que o povo de Israel estava no deserto, foi flagrado apanhando lenha em dia de sábado. Levado a Moisés e Aarão, o texto conta que o próprio Deus determinou que ele fosse apedrejado até a morte. E assim ocorreu. ${ }^{3}$

A Mishnah, compilação datada entre 70 e 200 de nossa Era, foi o primeiro documento que registrou a tradição oral do judaísmo, trazendo uma parte específica que já tratava dos eruvin, em seu segundo livro denominado Moed (festival).

A guarda do sábado veio a tornar-se de tal forma rigorosa que os mais sábios entre os rabinos foram forçados a distingüir entre as diferentes espécies de atividades proibidas, a fim de que os desastrosos resultados de uma obediência demasiado passiva pudessem ser evitados. Por exemplo, desde o período dos macabeus, quando mil israelitas preferiram morrer às mãos dos sírios do que empunhar armas e violar o sábado, e desde os tempos do cerco de Jerusalém por Pompeu, quando os defensores abandonaram os muros no momento em que a estrela do sábado apareceu no céu, foi decidido que lutar em defesa própria no dia do descanso era um ato legítimo. Da mesma forma, foi admitido que a observância do sábado poderia ser interrompida em vista de algum dever religioso superior, como a circuncisão ou a celebração de certas grandes festas. Também se permitia que a pessoa ajudasse, no sábado, alguém que corresse perigo de vida, mesmo que fosse um animal: (...) Mas os judeus mais rígidos não queriam saber desses subterfúgios diante da Lei, sendo esta uma fonte de discussão perene entre as diferentes escolas de doutores: o regulamento da comunidade dos essênios declara explicitamente que é melhor deixar que um animal ou mesmo um homem se afogue do que violar o sábado. ${ }^{4}$

Há diferentes entendimentos e críticas relacionados à questão dos eruvin. Aquilo que muitos diriam como uma forma de driblar as leis judaicas, ou como se traduz em Daniel-Rops (1983) subterfúgios de leitura da lei, também pode ser entendido como uma possibilidade de tornar a lei menos agressiva, já que daria ao praticante maiores chances de obedecê-la, sem, contudo, macular os mandamentos.

A rigorosidade da lei e sua inflexibilidade poderiam também torná-la inexecutável e a confiabilidade da própria religiosidade seria abalada, não houvesse essas propostas interpretativas que tornassem a lei viável e possível sem parecer um sacrifício ou algo desagradável. Estas adaptações são necessárias, porque estas leis foram estabelecidas em outros tempos. Estas adaptações dão vigor à lei e incentivam a continuidade das tradições, embora também não possamos ignorar que essas interpretações representem determinados grupos políticos e determinados interesses.

Apesar destas justificativas, ainda assim, há grupos ultraortodoxos que não aprovam os eruvin, justamente porque eles facilitam a vida no sábado. Mas não só isso, eles afirmam que é difícil reconhecer o espaço, pela dificuldade de visualizar os fios acima, nos postes.

\footnotetext{
${ }^{1}$ Êxodo 20, 8-11.

${ }^{2}$ Mateus 12, 1-8; Marcos 2, 23-28; Lucas 6, 1-5; Mateus 12, 9-13 ; Marcos 3, 1-6; Lucas 6, 6-11.

${ }^{3}$ Números 15, 32-36

${ }^{4}$ DANIEL-ROPS, pág. 225
} 
Alguns justificam sua impropriedade por utilizar um espaço público para fins religiosos, ou por violar os direitos humanos ao valorar de forma religiosa paredes e cercas de não judeus e que forçaria também não judeus a passarem por estruturas judaicas, mesmo que simbólicas. Há argumentos que apresentam a possibilidade de incentivar o antissemitismo, já que promove a separação e desencoraja a segregação ou de transformar o espaço em um gueto simbólico uso do espaço, além de incentivar o aumento da população judaica, pela formação do eruv. ${ }^{5}$

A possibilidade da mistura - eruv - na interpretação da lei judaica é uma dessas formas de ampliar a interpretação das leis concernentes ao shabat, tendo em vista os problemas que a observância da lei pode trazer. No que diz respeito, por exemplo ao eruv tavshlim, ele tenta eliminar problemas que possam ocorrer devido às restrições que acompanham os dias sagrados para preparo de alimentos.

No shabat, os alimentos são preparados de véspera, evitando a árdua tarefa que se impõe na cozinha para satisfazer as necessidades de todos os dias. Mas se houver um dia sagrado que exija a observância da lei do descanso e que se junte ao shabat sucedendo-se os dias sem intervalos, esta lei pode trazer graves prejuízos ao preparo da alimentação, já que seria preciso ter alimento pronto para muitos dias, não tendo como armazenar o alimento pronto, haja vista a sequência dos dias de descanso. Ao fazer o ritual do eruv será possível preparar a comida para o sábado sem ferir o mandamento.

O eruv tchumin (mistura de limites) tenta atender a necessidade daqueles que precisam viajar no shabat, mesmo que não possam usar meios de transporte, ampliando a possibilidade de espaço que se possa percorrer no dia sagrado. Este eruv é muitas vezes absorvido pelo eruv chatzerot que é o objeto de nosso estudo neste trabalho.

39 tipos de trabalho são definidos como proibidos de se executar no shabat. São ações que acompanham o dia a dia, como cozinhar, costurar, atividades agrícolas, de construção ou marceneiras e por aí afora. A $39^{\mathrm{a}}$ restrição diz respeito ao transporte de objetos, principalmente em espaço público. Por isso, há diversas observâncias com relação à checagem dos bolsos, por exemplo, onde sempre esquecemos alguma coisa e poderíamos incorrer na quebra do mandamento por sairmos de casa com algo que não nos déssemos conta.

Segundo as leis que orientam a guarda do sábado, não se deve, por exemplo, transportar objetos para fora de casa, mesmo que as chaves, ou transportar uma criança pequena em seu carrinho ou no colo. Da mesma forma óculos, lenço, bolsas e por aí afora. A restrição acontece, especialmente, com relação ao transporte de algo de sua casa para fora dela. Ou melhor, de um espaço privado para um espaço público.

A ideia do espaço privado (reshut rayachid) consiste em uma área cercada pelos quatro lados, em contraste com o espaço público ou coletiva (reshut harabim), que não seria murado. Só é possível transportar um objeto de um espaço privado para um espaço público até a distância que não chega a 2 metros $(1,92 \mathrm{~m})$. Ou seja, dentro de sua casa (espaço privado) é possível carregar os óculos, a bolsa ou empurrar o carrinho do bebê, mas fora dela não. Isto traz algumas consequências claras. Como ir à Sinagoga fazer as rezas, sem levar os óculos ou as chaves de casa?

Além das chaves de casa, do lenço, não é permitido também transportar objetos como comida ou mesmo bebida; as roupas de oração, como os xales; livros, medicamentos, roupas extras, fraldas, andadores, muletas e assim por diante.

Ao se recorrer ao eruv, o que se faz é misturar (arav) os espaços (chatzerot = pátios), de forma a considerar o que seria um espaço público em um espaço privado. Como se viu acima, a compreensão do espaço privado se dá pelo seu cercamento, que lhe imporia um limite. Mas como ampliar os limites para um espaço público como a rua?

\footnotetext{
${ }^{5}$ https://www.bbc.co.uk/religion/religions/judaism/customs/eruv 1.shtml, acessado em 02 de fevereiro.
} 
A solução para o problema surgiu a partir da fixação de um fio que, por cima dos postes delimitaria seu espaço, mas se aproveita também limitações que já existam, como linhas ferroviários, paredes ou sebes. O fio de arame ou nylon que se coloca por sobre os postes, teria o efeito de fechar as áreas abertas, por assim dizer, embora um fio sobre o poste não seja suficiente para fechar uma área, mas simplesmnte demarcá-la. $O$ fio seria quase que imperceptível de um modo geral, primeiramente porque ele estaria acima dos olhos, passando por sobre os postes. Sua delimitação seria simbólica, na verdade. Embora também separado dos outros fios que encontramos nas vias públicas, como fios de eletricidade ou telefonia, ele se confundiria no olhar com um desses. Por isso, Myer Siemiatvcki (2005), define:

O eruv é uma linha imaginária que cerca um determinado espaço, apesar de ter alguns itens que sinalizam sua existência (como pequenos cartazes em postes de energia, adesivos em árvores e/ou postes especialmente colocados para isso, lugares naturais como rios, lagos e montanhas). ${ }^{6}$

Sem este eruv, o espaço físico de um judeu religioso se resumiria a sua casa em tempo de shabat, significando seu confinamento. Este recurso lhe permite maior espaço de ação e integração junto à comunidade onde vive. Topel (2013) destaca a posição de alguns estudiosos que entendem o eruv não como um espaço de ampliação de liberdade, mas como um cerco, que evidenciaria o contraste entre o sagrado e o profano.

Mas é preciso considerar que o eruv, embora real, é um espaço imaginário ${ }^{7}$, e, como enfatiza Siemiatycki (2005) é preciso fé e imaginação para acolher esta percepção de espaço privado expandido. A existência do eruv muitas vezes não é perceptível mesmo à própria comunidade religiosa, como se vê: "Por falta de informação, muitas pessoas não sabem que só era permitido carregar naquelas cidades por causa do eruv existente" 8 . Por isso é que se aconselha que os rabinos sempre lembrem a comunidade sobre a existência e atividade do eruv local.

Como espaço imaginário, é preciso entender que o eruv também só se concretiza pela religiosidade. Fora do período de obediência às leis de Shabat, o eruv é o espaço costumeiro por onde se circula sem qualquer preocupação, é o espaço onde a vida acontece. Ele se redimensiona pela necessidade religiosa de ampliar seu espaço. Embora seja o espaço de todos os dias, ele ganha um sentido especial que permite conjugar fé e vida.

E é, realmente, difícil elaborar a ideia de um espaço de circulação comum, que em determinados momentos (dias sagrados) são delimitados e devem ser vistos como espaços sagrados. Principalmente quando este espaço é compartilhado com outras pessoas que mantém uma relação diferenciada.

Mas é bom observar que não basta, por conta própria, comprar um fio e subir nos postes demarcando áreas! A demarcação deste limite precisa ser aprovada por um tribunal rabínico e obedecer a legislação vigente no local. Em São Paulo e no Rio de Janeiro é possível encontrar bairros demarcados desta forma com esta finalidade ${ }^{9}$. Estes espaços são constantemente fiscalizados, a fim de consertar eventuais rupturas do fio, o que significaria a ineficácia do eruv, ou sua inatividade.

\footnotetext{
${ }^{6}$ Topel, M. F. (2013). O "eruv" na Europa, nos Estados Unidos e no Brasil: novas estratégias de demarcação do espaço judaico. Cadernos De Língua E Literatura Hebraica, (10), 153-164.

${ }^{7}$ Second, leaps of imagination and faith are required to re-interpret this expansive eruv territory as private space massively extending the realm of one's home. In this instance an entire community agrees to cognitively reconstruct as private, space otherwise understood to be public.

${ }^{8}$ DICHI, Isaac. Shomer shabat: leis referentes ao shabat. $2^{a}$. Edição revisada e ampliada. RJ: Book Rj., pág 121.

${ }^{9}$ Sobre o Eruv São Paulo: https://bdk.com.br/eruv/1 , acessado em 02 de fevereiro de 2021. Sobre o eruv no Rio de Janeiro: http://www.kolelrio.com.br/index.php/eruv-copacabana/, ou

http://www.kolelrio.com.br/index.php/eruv-ipanema/, acessados em 02 de fevereiro de 2021.
} 
O eruv do Rio de Janeiro foi inaugurado em 2013, compreendendo o bairro de Copacabana, mas foi ampliado, desde então, alcançando hoje uma área que vai de Copacabana até a Gávea. O órgão responsável pela fiscalização e cuidado deste eruv é o Kolel Rio, uma instituição criada em 2001 que labuta pelos valores judaicos.

Esta delimitação só fará sentido, no entanto, para um judeu ortodoxo que cumpra o mandamento da guarda do sábado, mas será poderá ser totalmente ignorado por um judeu que não seja religioso ou qualquer outra pessoa qualquer que não seja judia. Para estes, pouco importará que haja fio que demarque algum espaço.

Para os religiosos que guardam as leis referentes ao sábado, é preciso sempre consultar na véspera de um dia sagrado se o eruv está ativo ou não. O que significa dizer se houve algum rompimento do fio que delimita a área e se houve ou não o reparo em tempo hábil para entender o espaço privado por ocasião do dia sagrado. Se algum problema ocorreu de forma a danificar esta ligação, o eruv é considerado inativo e não se poderá aplicar a definição de espaço privado na área estabelecida.

Outra questão que vale a pena ressaltar é que a ideia do eruv só é, de fato, útil para o cumprimento das leis de Shabat e não fará a menor diferença em dias normais, para os quais as leis do Shabat referentes ao trabalho não se impuserem. Ou seja, este espaço delimitado não promove qualquer efeito em dias que não sejam sagrados. Ultrapassá-los ou não, carregar objetos ou não, não farão a menor diferença em dias comuns.

Isso é importante para que não se confunda os limites de um eruv com a formação de bairros judeus propriamente ditos. Eles não têm uma função protetiva ou preventiva dos grupos judeus, mas objetivam simplesmente tornar menos duras as leis de observância do Shabat, como um incentivo à guarda de suas leis. Por isso, entende-se que a comparação do eruv a um gueto, pode ser uma percepção precipitada.

Segundo Wacquant:

O termo "gueto" denota uma área urbana restrita, uma rede de instituições ligadas a grupos específicos e uma constelação cultural e cognitiva (valores, formas de pensar ou mentalidades) que implica tanto o isolamento sócio-moral de uma categoria estigmatizada quanto o truncamento sistemático do espaço e das oportunidades de vida de seus integrantes. ${ }^{10}$

Tais áreas formam-se naturalmente para preservar hábitos culturais e com funções específicas. Mas este espaço também funciona como espaço de poder e cerceamento. Gueto deriva do italiano

giudecca, borghetto ou gietto (ou do alemão gitter ou do hebreu talmúdico get, de etimologia controversa), a palavra "gueto" inicialmente se referia à consignação forçada de judeus a distritos especiais por parte de autoridades políticas e religiosas da cidade. ${ }^{11}$

$\mathrm{Na}$ caracterização do gueto, Wacquant destaca quatro elementos: estigma, limite, confinamento espacial e encapsulamento institucional. Embora possa ser uma demonstração de poder religioso, demarcando a área do sagrado, faltaria ao espaço do eruv os outros elementos necessários para a sua caracterização como um gueto.

\footnotetext{
${ }^{10}$ WACQUANT, Loïc. Que é gueto? Construindo um conceito sociológico. Rev. Sociol. Polit., Curitiba, n. 23, p. 155-164, Nov. 2004 . Disponível em: <http://www.scielo.br/scielo.php?script=sci_arttext\&pid=S0104-44782004000200014\&lng=en\&nrm=iso>. access on 01 Feb. 2021.

${ }^{11}$ Idem.
} 
A compreensão do espaço do eruv, pode ser melhor entendida a partir de Foucault ${ }^{12}$. Ele identifica dois tipos de espaços. Um, a que chama de utopia, por não apresentar um local real. No contingente cultural judaico este espaço se realiza na figura de Sião, primeiramente associada à Jerusalém e, mais adiante associado ao estado de Israel, mas que excede este entendimento, porque supõe um Israel ideal. Entre os cristãos, a simbologia de Sião designa o céu, ou a morada de Deus.

Foucault identifica um outro espaço a que chama heterotopia. Composto pelo prefixo grego heteros que designa diferente e por topia que significa lugar, espaço, o termo pode ser entendido como espaço do outro, associando hetero a alter. Este seria uma espécie de lugar que está fora de todos os lugares, embora seja efetivamente localizável. ${ }^{13}$

Para melhor caracterizá-lo, ele usa a ideia do espelho naquilo que reflete e que é refletido. A imagem que se reflete no espelho é o não lugar, a utopia, mas, ao mesmo tempo uma heterotopia,

na medida em que o espelho existe realmente, e que tem, no lugar que ocupo, uma espécie de efeito retroativo; é a partir do espelho que me descubro ausente no lugar em que estou porque eu me vejo lá longe. A partir desse olhar que de qualquer forma se dirige para mim, do fundo desse espaço virtual que está do outro lado do espelho, eu retorno a mim e começo a dirigir meus olhos para mim mesmo e a me constituir ali onde estou: o espelho funciona como uma heterotopia no sentido em que ele torna esse lugar que ocupo, no momento em que me olho no espelho, ao mesmo tempo absolutamente real, em relação com todo o espaço que o envolve, e absolutamente irreal, já que ela é obrigada, para ser percebida, a passar por aquele ponto virtual que está lá longe. ${ }^{14}$

Como se pode ver, o eruv funciona como este espaço heterotópico e se identifica com a imagem do espelho. Ele une dois espaços: um imaginário e outro real. Para alguns que partilham deste espaço não haverá nunca diferença entre eles, porque não há uma identificação cultural com ele, nem se vê funcionalidade nele. No entanto, para aqueles que partilham do mesmo sentimento religioso, este espaço é ressignificado, atendendo aos seus anseios.

O espelho, em sua projeção virtual e ilusória, apresenta uma manifestação utópica e encapsulada do reflexo humano, na ocasião de um agrupamento hermético e limitado. Mas, paradoxalmente, apesar de concentrar esse ilusionismo, o espelho possibilita o resgate da imagem humana evocada em suas paredes e, consequentemente, promove a experiência de unir duas realidades completamente alternativas em seu jogo ${ }^{15}$

Mas, apesar deste espaço parecer quase invisível aos não judeus e até mesmo para judeus não religiosos ou que não façam a guarda do shabat, Topel (2013) destaca existência de ações judiciais nos EUA que contestam as demarcações dos eruvin, o que demonstra que estes espaços não são assim tão irreais ou invisíveis. ${ }^{16}$

\footnotetext{
${ }^{12}$ FOULCAULT, Michel. Outros espaços. In: Estética: literatura e pintura, música e cinema. Organização e seleção de textos: Manoel Barros da Motta; tradução Inês Autran Dourado Barbosa. 2a . Ed, Rio de Janeiro: Forense Universitária, 2009

${ }^{13}$ Idem, pág. 415.

${ }^{14}$ Idem, ibidem.

${ }^{15}$ KRÜEGER JUNIOR, 2016.

${ }^{16}$ Em Hamptons, 2011, https://www.wsj.com/articles/BL-METROB-11705
} 


\section{REFERÊNCIAS BIBLIOGRÁFICAS}

DANIEL-ROPS, Henry. A vida diária nos tempos de Jesus. São Paulo: Vida nova, 1983.

DICHI, Isaac. Shomer shabat: leis referentes ao shabat. 2a . Edição revisada e ampliada. RJ: Book Rj.

FOULCAULT, Michel. Outros espaços. In: Ditos e escritos III: Estética: literatura e pintura, música e cinema. Organização e seleção de textos: Manoel Barros da Motta; tradução Inês Autran Dourado Barbosa. 2a . Ed, Rio de Janeiro: Forense Universitária, 2009. Pág 411 - 422.

KRÜGER JUNIOR, Dirceu. Foucault: a heterotopia como alternativa para pensar o espaço social. Ano 1 Enciclopédia Pelotas. V.05, pág. 22 - 37, inverno 2016

SCHLAFF, Shiraj. Using an eruv to untangle the boundaries of the supreme court's religionclause jurisprudence. Disponível em:

https://scholarship.law.upenn.edu/cgi/viewcontent.cgi?article $=1390 \&$ context $=$ jcl, acessado em 02 de fevereiro de 2021.

SIEMIATYCKI, M. Contesting sacred urban space:The case of the Eruv . Int. Migration \& Integration 6, 255-270 (2005).

TOPEL, M. F. O "eruv" na Europa, nos Estados Unidos e no Brasil: novas estratégias de demarcação do espaço judaico. Cadernos De Língua E Literatura Hebraica, (10), 153-164. (2013)

WACQUANT, Loïc. Que é gueto? Construindo um conceito sociológico. Rev. Sociol.

Polit., Curitiba, n. 23, p. 155-164, Nov. 2004. Disponível em:

$<$ http://www.scielo.br/scielo.php?script=sci_arttext\&pid=S0104-

$44782004000200014 \& \operatorname{lng}=$ en\&nrm=iso $>$. access on 01 Feb. 2021. 